\title{
Employee Engagement a Conundrum in Indian Information Technology Companies
}

\author{
Rajeesh Viswanathan, Sarath Lal, Jahira Parveen
}

\begin{abstract}
Employee engagement is the level of employees psychological involvement towards the organization and its values. It is learnt that when an employee is engaged, the employee is aware of his responsibilities and how it impacts the organizations vision. Current study intends to study the level of employee engagement of select IT companies in India.

Top 05 companies were chosen from Chennai and Bangalore on the basis of NASCOM report. Study looked into various factors and the prevailing strategies adopted by the companies that facilitated employee engagement. Variables like Organizational climate, leadership, Job satisfaction, Employee Commitment and Employee Engagement were studied. The sample data was obtained from five major IT organizations in Chennai and Bangalore region. Selected organizations mainly comprises of the Software Developer's Team under the Self Managed Team base.

From the PLS model done, the study suggest the companies that the manifest variables organizational climate, employee commitment, leadership style and job satisfaction has a good loading and contributes to employee engagement in an effective way and the companies need to concentrate on these variables to achieve employee engagement.
\end{abstract}

Originality/value- This study provides insightful findings in understanding the role of organizational competencies like job satisfaction and employee commitment play in facilitating employee engagement. This study also shows the importance of the demographic variables with employee's engagement. In spite of the limitations of the research, the study contributed to the international human resources management by exploring the South Indian IT company's context. The theoretical framework proposes the relationship between employee engagement, job satisfaction and employee commitment. The study has found that job satisfaction and employee commitment is correlated with employee engagement and serves as the important indicator for engaging employees.

Index Terms: Employee Engagement, Job Satisfaction, Employee Commitment

\section{INTRODUCTION}

Globally employee engagement had develop drastically and had earned the attention of HR professionals. In the modern business environment, the mangers demand for higher productivity by increasing efficiency when compared with previous year. With this higher pressure the organization are making a full and pure effort to increase their employees. Performance to increase the organizations among the competitions. Once it was easy to implement because there were employees who are satisfied with their organization and

Revised Manuscript Received on July 05, 2019.

Dr. Rajeesh Viswanathan, Assistant Professor, Dept of International Business, School of Management, Pondicherry University, Pondicherry, India.

Sarath Lal, Research, Scholar, Dept of International Business, School of Management, Pondicherry University, Pondicherry, India.

Dr. Jahira Parveen, Assistant Professor, Faculty of Management, SRM Institute of Technology, Chennai. had work experience and stayed in the company for a longer period of time and contributed to the organization and thereby there was an increase in productivity. But the situation have been changed because satisfied employees are not enough to meet the demands and lead to high performance in the increasing business environment and competition.

The organizations have realized that in today's global environment, human resource management is the mainly concentrated term by which attracting, retaining and keeping them committed and mostly 'engaging' to reach the organizational goals. An engaged employee acts an ambassador for the company and they do not shift from one organization to the other organization and they are able to produce better performance and increase productivity. This can be achieved only when the employees think their organization as their own and respects the work given to them and contributes to performance and with all these they should have a personal growth along with the organization.

Employee engagement is always an advantage for the organization in today's business environment which is competitively enough. But in India, the importance of employee engagement is different due to variety of reasons like diverse environment in each organization, leadership style followed by the managers, how committed and satisfied they are in the work they do and with the organization. Considering these, the present study intends to concentrate on the climate and leadership style in the organization and satisfaction level and commitment level of the employee in the organization.

\section{REVIEW OF LITERATURE}

Kahn added to a meaning of engagement to incorporate "the job that is synchronous, articulation of a man's "favored self" in undertaking methods that elevate associations with work additionally, with other individuals, specific vicinity (real, subjective, and passionate) and powerful, complete exhibitions" (Kahn, 1990). For Kahn, the people's engagement inside their part had been showed by the conjecture of on their own across the three measurements. Verifiable in this meaning could be the thought that the worker's engagement is mirrored by the conjecture of specific energies inside their component that may alter as recommended by the variables being logical prerequisites of this part. To spell it out this notion, Kahn depicted a scuba plunging trainer who displayed snippets of engagement through all the three proportions amid a campaign that is plunging. The instructor utilized himself actually, by checking adjust and driving the jump; subjectively, whenever you're very carefully aware of jumpers, climate, and

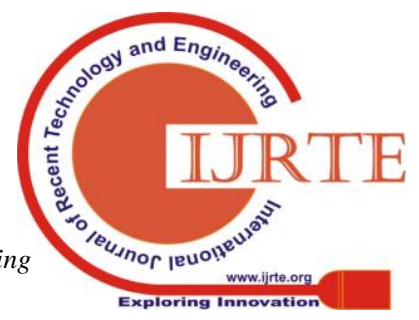


life that is marine and inwardly, by their eagerness and compassion for just about any jumpers that are youthful were both stimulated and frightful. Having said that, specific withdrawal is the uncoupling of self from component and is shown by an absence of physical relationship, subjective cautiousness, and passionate endeavor (Kahn, 1990). These processes underlie precisely what analysts have actually described as automatic or programmed (Hochschild, 1983), burnout (Maslach, 1982), unresponsive, segregated (Goffman, 1959, 1961), or effortless (Hackman and Oldham, 1980). Kahn portrayed an example of withdrawal with someone's part in the activity and contemplations of a modeler that is senior relegated projects to subordinates, embraced a spur for the minute approach to contend with work, and neglected to grasp sincerely unite with clients or designers.

Maslach and Leiter (1997) at first characterized the engagement develop whilst the inverse of burnout (put another way, somebody who is maybe not work that is experiencing should be occupied employing their career.) Luthans and Peterson (2002) explained on Kahn's work with worker engagement, gives a hypothesis that is vocalized Gallup's experimentally inferred worker engagement. They opined that that to be candidly drawn in is always to shape associations which are mate people and also to experience compassion for them. Interestingly, being intellectually linked to allude to the folks who are exceedingly mindful of these objective that is the main plus in their workplace. Essentially Dvir, Eden, Avolio, and Shamir (2002,) characterized engagement that is effective far as "high degrees of movement, task, and duty." Schaufeli et al. (2002) characterize Employee Engagement as "a satisfying that is good company associated condition of the head that is described by force, commitment and assimilation". They facilitate declare that engagement just is not a flashing and declare that is particular, but rather is "a far more industrious and pervasive psychological - intellectual express which can be perhaps not centered on a specific article, occasion, specific, or conduct" Harter, Schmidt and Hayes (2002) characterize worker engagement as "the typical average person's relationship along with this, satisfaction with and likewise eagerness for work ". Hewitt (2004) characterizes worker engagement because the worker yearning to state (talk positively with regards to the business), remain (craving become a person through the relationship) and undertaking (go during the night normal for the company) Mount, Harter, Witt, and Barrick (2004) characterized engagement as far as a "high inside motivational state." Wellins and Concelman (2004) claim that "Employee Engagement could be the power that is illusive rouses workers to more elevated quantities of execution. This pined for vitality is an amalgam of responsibility, reliability, effectiveness a proprietorship." they assist included so it includes, "emotions what's more, demeanors workers have actually towards their employments and their company."Robinson, Perryman and Hayday (2004), characterize "engagement as a demeanor that is inspirational by the agent towards the partnership and its characteristics that are particular. A drew in worker understands the continuing business climate, works together associates to enhance execution inside the benefit any benefit of the organization". They encourage consist of that relationship must produce and support engagement that will be a two course relationship in the center of employer and worker.
Lucey, Bateman and Hines (2005) have deciphered that "Employee Engagement will be the means through which each join that is individual the corporation along with customers "" Improvement Dimensions International (DDI), (2005), characterizes worker Engagement as "the quantity to which people esteem, appreciate and place stock in whatever they do.

\section{METHODOLOGY}

All units pertaining to a study is called a population and the sample is the subset of a population. According, to NASSCOM report, the top 5 companies were listed and from this companies the samples were chosen. The questionnaire had two sectors. The first section consists of the demographic data to be collected from the respondents. The second section consists of the statements measuring Organizational climate, leadership, Job satisfaction, Employee Commitment and Employee Engagement. The Scale was measured from a score of 5 to 1 with strongly disagree to strongly agree using five point Likert's Scale, where higher score represents "Strongly agree" and the lesser gives "Strongly Disagree". The data collected is analyzed with the statistical tools using SMART PLS.

\section{ANALYSIS}

\section{Partial Least Square Method:}

Data analyses have been conducted with the use of systematic application of Smart PLS version 3.0

Using PLS, analyses has been carried out in two stages

1. PLS measurement model

2. PLS structural model

PLS structural model is based on the study constructs obtained from a contemporary factor analysis (CFA) Generally measurement model evaluates the relation amongst the manifest variables and the latent variables Validity and reliability of the construct measures are evaluated before evaluating the relationships between the latent variables in the PLS model.

Two stages have been used here: first, individual item reliabilities are determined and secondly, the three types of validity are explained: convergent validity, construct validity and discriminant validity. The measurement model in this study consists of reflective measures.

Quality criteria are required such as path coefficients $(\beta)$, the average variance extracted (AVE), composite reliability (CR) which exceed .50 in our analysis. The factor loadings All items are loaded significantly $(>.50)$ on the reflective factors which are an indication of individual reliability. The Uniform factor loadings form constructs to indicators are greater than 0.5 (ranging from $0.76-0.95$ ), indicating that reliabilities of the items are acceptable.

\section{PLS Model Based Measures of Validity}


PLS Analysis Allows for Three ways of investigating validity:

A) Convergent Validity; B) Construct Validity;
C) Discriminant Validity and these are found to be satisfactory.

\begin{tabular}{|l|l|c|c|c|c|}
\hline S. NO & Construct & $\begin{array}{l}\text { No of } \\
\text { Items }\end{array}$ & $\begin{array}{l}\text { Reliability } \\
\text { (Cronbachs Alpha) }\end{array}$ & $\begin{array}{l}\text { Composite } \\
\text { Reliability }\end{array}$ & AVE \\
\hline 1 & Organizational climate & 25 & 0.970 & 0.973 & 0.754 \\
\hline 2 & Leadership style & 11 & 0.961 & 0.965 & 0.622 \\
\hline 3 & Employee commitment & 12 & 0.975 & 0.977 & 0.756 \\
\hline 4 & Job satisfaction & 14 & 0.945 & 0.952 & 0.645 \\
\hline 5 & Employee engagement & 17 & 0.975 & 0.977 & 0.629 \\
\hline
\end{tabular}

Construct Validity: The Study used well defined scales from previous research. Correlating question items is appropriate technique to measure weather construct validity holds (Campbell and Fiske, 1959). The table show that correlations between the constructs are not highly correlated with highest correlations among the principle constructs at $r=799$.

Discriminant Validity: Discriminant validity is verified by equating the square root of average variance extracted (AVE) and its correlations with other latent constructs. Evidence of discriminant validity happens when square root of the variance extracted estimation outdoes the correlations between the factors making (Fornell\&Larcker 1981).

\begin{tabular}{|l|l|l|l|l|l|}
\hline Constructs & OC & LS & EC & JS & EE \\
\hline OC & $\mathbf{0 . 7 4 6}$ & & & & \\
\hline LS & 0.233 & $\mathbf{0 . 7 6 3}$ & & & \\
\hline EC & 0.145 & 0.172 & $\mathbf{0 . 8 5 1}$ & & \\
\hline JS & 0.059 & 0.185 & 0.027 & $\mathbf{0 . 7 4 9}$ & \\
\hline EE & 0.616 & 0.088 & 0.309 & 0.276 & $\mathbf{0 . 8 1 6}$ \\
\hline
\end{tabular}

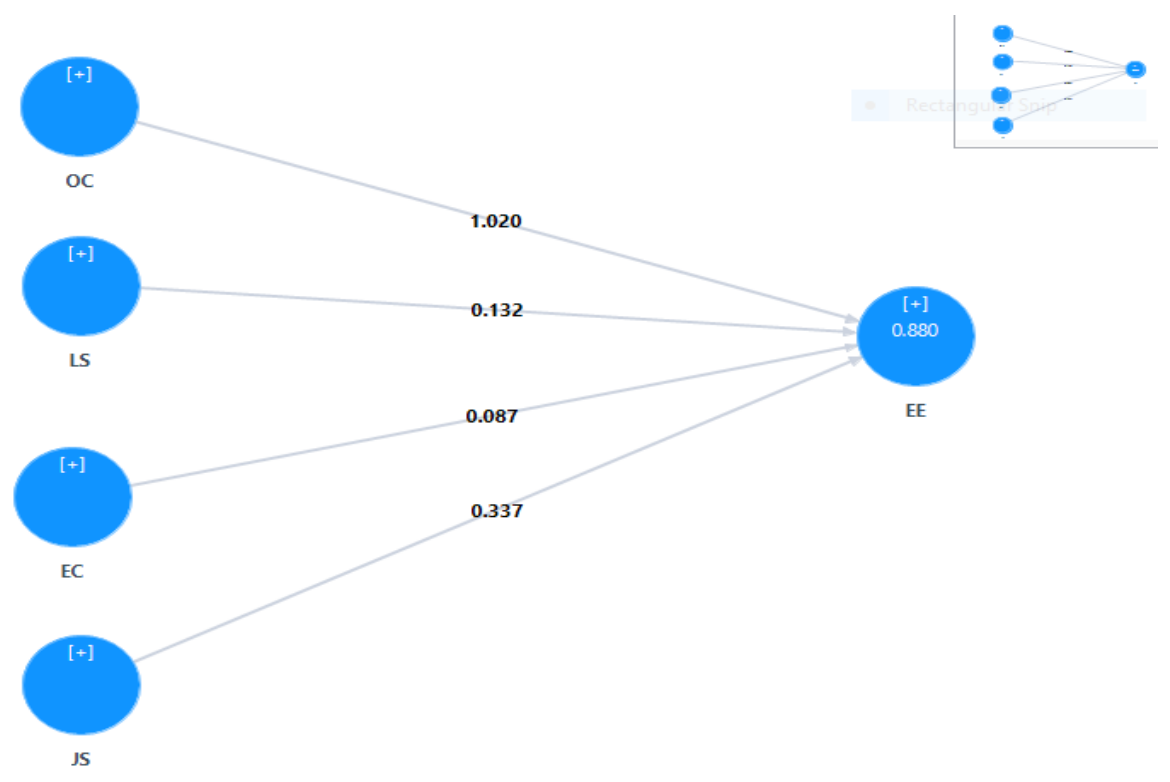

Figure 5.1: PLS Structural Model

In order to test whether hypotheses are significant, the significance of path coefficients (â) and t-statistics estimated in the PLS model are used.

Table 5.32: The Overall Bootstrap Outputs of the Means, T-Statistics and P Values.
The structural Model states relationship between latent constructs. The Structural path estimates $(\beta)$ and $t-$ static for hypothesis testing are examined using a bootstrapping method for assessing the statistical significance of the structural path estimates.

As well, cross validated redundancy $\left(\mathrm{Q}^{2}\right)$ measure are assessed using a PLS blindfold method for exploring predictive relevance in the quality of the path Model. Figure reports the path coefficients $(\beta)$ for the resulting latent variable and $\mathrm{R}^{2}$ for the dependent variable. The coefficients of the hypothesized paths are significant with predictive relevance. The proposed conceptual model has an $\mathrm{R}^{2}$ of $0.880 \%$ for employee engagement construct.

All relationships among the constructs and $\mathrm{R}^{2}$ are significant and reach satisfactory levels. The results support that the structural model has predictive power (Chin et al. 1996; 2003). 
Employee Engagement a Conundrum in Indian Information Technology Companies

\begin{tabular}{|l|l|l|l|l|l|}
\hline Hypothesis & & $\begin{array}{l}\text { Original Sample } \\
(\mathrm{O})\end{array}$ & T Statistics(O/STERRI & P Value & Accepted/ Rejected \\
\hline H3a & OC $\rightarrow \mathrm{EE}$ & 1.020 & 18.481 & 0.000 & Accepted \\
\hline H3b & LS $\rightarrow \mathrm{EE}$ & 0.132 & 3.473 & 0.001 & Accepted \\
\hline H3c & EC $\rightarrow$ EE & 0.087 & 0.949 & 0.002 & Accepted \\
\hline H3d & JS $\rightarrow$ EE & 0.337 & 3.556 & 0.000 & Accepted \\
\hline
\end{tabular}

The PLS structural model is primarily evaluated by the $\mathrm{R}^{2}$ of endogenous latent variable and $\mathrm{t}$ - statistics (Chin 1998; Tenenhaus et al. 2005). The PLS model evaluation is centred on non- parametric methods which are based on prediction oriented because PLS method marks no distributional assumptions parameter estimate (Chin 2001). Thus, PLS path modelling does not account any kind of fit indices like TFI or CFI as with covariance based structural equation modelling (SEM).

\section{V.FINDINGS}

In the PLS Model, the convergent validity is tested and AVE is found to be greater than 0.05 and in this study it varies from 0.622 to 0.754 . The construct validity is found with an $r$ value of 799 and the discriminant validity is also found. Then the PLS Structural Model is done to find the relationship of the latent constructs and the $\mathrm{R}$ square of employee engagement is found to have $0.880 \%$ and the relationship among the constructs are found to be significant.

Then, the blindfolding procedure is being carried out and the $\mathrm{Q}$ square value is found to be greater than 0 with a value of 0.545 .

From the PLS model done, the study suggest the companies that the manifest variables organizational climate, employee commitment, leadership style and job satisfaction has a good loading and contributes to employee engagement in an effective way and the companies need to concentrate on these variables to achieve employee engagement.

\section{LIMITATIONS}

- Cross Sectional design may hamper the applicability of the causal conclusions drawn from our findings.

- The study relied on the questionnaire to collected data. Observation and Interview method is could not be carried out in the study because of the geographical distance.

- The study focused only on IT industry therefore generalization to other expatriates working in other industries should be done with care.

- There could be bias in the responses as all the responses are based on the perception of the respondents.

- Since it is a comprehensive study, exploring single construct in-depth is not feasible the study presents an overall view of expatriate adjustment and performance.

\section{SUGGESTION FOR FUTURE RESEARCH}

Future studies must try to include to collect data from various other sources such as spouses of expatriates and children of the expatriates, colleagues, and supervisors. In the future, more instead of cross sectional study longitudinal studies must be conducted to generate rich data collected over a period of time which will give more insights in the adjustment patterns over a period of time and its impact on the study variables. Since the data was collected from the four cities, the findings to other employees working in worker cities in India can be done

\section{REFERENCES}

[1] Ahlstrom, D., \& Druton, G. D.,. International management strategy and culture in the emerging world. Mason, USA: South-Western Cenage Learning (2010).

[2] Chen, A. S., Lin, Y., \& Sawangpattanakul, A., International Journal of Intercultural Relations The relationship between cultural intelligence and performance with the mediating effect of culture shock : A case from Philippine laborers in Taiwan. International Journal of Intercultural Relations, 35(2), 246-258 (2011) doi:10.1016/j.ijintrel.2010.09.005

[3] Ghauri, P., \& Gronhaug, K., Research methods in business studies (3 ed.). England: Prentice Hall Financial Times (2005).

[4] Hair, J. F., Black, W., Babin, B. J., \& Anderson, R., Multivariate data analysis: A global prespective (Seventh ed.). Delhi: Pearson (2010).

[5] Hechanova, R., Beehr, T. A., \& Christiansen, N. D., Antecedents and Consequences of Employees 'Adjustment to Overseas Assignment : A Meta-analytic Review, 52(2), 213-236 (2003).

[6] Kothari, C. R., \& Garg, G., Research Methodology. New Delhi, India: New Age International Publishers (2013).

[7] Kraimer, M., An Examination of Perceived Organizational Support as a Multidimensional Construct in the Context of an Expatriate Assignment. Journal of Management, 30(2), 209-237 (2004). doi:10.1016/j.jm.2003.01.001

[8] Lane, H. W., \& Distefano J. J.: Maznevski, M. L., International management behavior: text, readings, and cases ( 5 ed.). Malden, MA, USA: Blackwell Publishing (2006).

[9] Lazarova, M., A model for the influence of social interaction and social support on female expatriates cross- cultural adjustment A model for the in uence of social interaction and social support on female, 5192 (November 2015). doi:10.1080/09585190210125903

[10] Maylor, H., \& Blackmon, K., Researching business and management. London: Palgrave macmillian, 2005.

[11] Osman-gani, A. M., \& Rockstuhl, T., Antecedents and Consequences of Social Network Characteristics for Expatriate Adjustment and Performance in Overseas Assignments : Implications for HRD, 7(1), 32-57 (2008). doi:10.1177/1534484307312182

[12] Wong, C. S., \& Law, K. S., The effects of leader and follower emotional intelligence on performance and attitude:An exploratory study, The Leadership Quarterly, 13, 243-274 (2002).

[13] Wua, P. C., \& Ang, S. H., Singapore, The impact of expatriate supporting practices and cultural intelligence on cross-cultural adjustment and performance of expatriates in Singapore, The International Journal of Human Resource Management, 22(13), 2683-2702 (2011)

[14] Zikmund, G. W., Business research methods, New Delhi: CENGAGE learning (2003). 